\title{
Síndrome de Lemierre y Mycoplasma pneumoniae
}

\author{
M. RIVERO MARCOTEGUI, C. SÁNCHEZ RODRÍGUEZ', S. CABAL SOTO², \\ M. AIZCORBE GARRALDA ${ }^{3}$ \\ Servicio de Medicina Interna. Clínica Ubarmin. Elcano. Pamplona. Servicios de \\ ${ }^{1}$ Radiología, ${ }^{2}$ Análisis Clínicos y ${ }^{3}$ Cirugía General. Hospital Virgen de Camino. Pamplona
}

\author{
LEMIERRE'S SYNDROME AND MYCOPLASMA PNEUMONIAE
}

\section{RESUMEN}

Se ha sugerido que una infección faríngea previa viral o bacteriana puede favorecer el desarrollo del síndrome de Lemierre, una entidad hoy en día poco frecuente. Se describe un caso de síndrome de Lemierre en el que coexiste una infección por Mycoplasma pneumoniae, hecho comunicado en la literatura sólo en otros 2 casos.

Se trata de una adolescente de 16 años con tromboflebitis yugular izquierda, bacteriemia por Fusobacterium necrophorum y émbolos sépticos en pulmón, que requirió ventilación mecánica por insuficiencia respiratoria grave. A pesar del tratamiento precoz con penicilina $\mathrm{G}$ y clindamicina, persistió la fiebre y parte de la afectación pulmonar hasta la introducción, tras la confirmación serológica de infección por M. pneumoniae, de un antibiótico activo frente a este patógeno.

Los clínicos debemos saber reconocer fácilmente esta enfermedad porque su presentación clínica es muy característica, y debemos considerar la posibilidad de coinfección con otros microorganismos, incluido $M$. pneumoniae.

PALABRAS CLAVE: Síndrome de Lemierre. Fusobacterium necrophorum. Mycoplasma pneumoniae.

\section{ABSTRACT}

It has been suggested that a previous viral or bacterial pharyngitis may predispose to Lemierre's syndrome, an uncommon entity nowadays. A case of Lemierre's syndrome and co-infection with Mycoplasma pneumoniae is described, association published before in only 2 other cases.

A 16-year-old girl with trombophlebitis of the left jugular vein, Fusobacterium necrophorum bacteremia and septic emboli in the lung requiring mechanical ventilation due to severe respiratory insufficiency. Despite early treatment with penicillin $G$ and clindamycin, fever and part of pulmonary affectation persisted until that an antibiotic agent active against $\mathrm{M}$. pneumoniae was instaurated, after its serological confirmation.

The physicians should be easily recognized this disease because of its characteristic clinical findings, and co-infection with other organisms including M. pneumoniae, should be considered.

KEY WORDS: Lemierre's syndrome. Fusobacterium necrophorum. Mycoplasma pneumoniae.

Rivero Marcotegui M, Sánchez Rodríguez, C, Cabal Soto S, Aizcorbe Garralda M. Síndrome de Lemierre y Mycoplasma pneumoniae. An Med Interna (Madrid) 2005; 22: 541-543.

\section{INTRODUCCIÓN}

Las infecciones faríngeas en personas jóvenes y sanas suelen estar causadas por virus, ocasionalmente por bacterias, $\mathrm{y}$ raramente se acompañan de bacteriemia o causan enfermedad grave. En 1936, Lemierre (1) describió un cuadro de sepsis fulminante en adolescentes y jóvenes sanos consistente en tromboflebitis séptica de la vena yugular interna y abscesos metastásicos múltiples, generalmente en pulmón, secundaria a una infección orofaríngea aguda por bacterias anaerobias, habitualmente Fusobacterium necrophorum. Tras la introducción de los antimicrobianos y de su extendido uso en el trata- miento de las infecciones faríngeas disminuyó sustancialmente la incidencia de esta infección (2).

El motivo por el que $F$. necrophorum, comensal habitual de la cavidad oral, puede ser tan agresivo no es bien conocido. Se han descrito varios casos de síndrome de Lemierre precedidos de infección por otros microorganismos, especialmente por el virus Epstein-Barr (VEB) (3-5), sugiriéndose que una infección primaria faríngea viral puede favorecer el desarrollo del cuadro.

Describimos un caso de síndrome de Lemierre con severa afectación pulmonar para recordar una entidad que parece estar aumentando en los últimos años $(3,6,7)$ y en el que coe- 
xiste una infección aguda por Mycoplasma pneumoniae, hecho que sólo hemos visto descrito en la literatura en otros 2 casos $(8,9)$ (revisión de la base de datos MEDLINE desde 1980 hasta el 1 de marzo de 2005; palabras clave: «Lemierre's syndrome» and «Fusobacterium necrophorum» and «Mycoplasma pneumoniae»).

\section{CASO APORTADO}

Paciente de 16 años que acudió al servicio de urgencias por presentar desde hacia 2 días dolor de garganta, fiebre, escalofríos, vómitos y dolorimiento epigástrico. Tras la realización de una analítica básica y de una radiografía de tórax que fueron normales fue diagnosticada de un cuadro pseudogripal no prescribiéndose ningún tratamiento farmacológico. Tres días más tarde la paciente acudió de nuevo a urgencias al persistir la fiebre y odinofagia y presentar dolor intenso en cara lateral izquierda de cuello, dolor subescapular derecho con la inspiración, sensación disneica y molestias abdominales difusas. Negaba hábitos tóxicos y no había presentado enfermedad previa de interés. A su ingreso la enferma estaba consciente, eupneica, la temperatura axilar era de $39^{\circ} \mathrm{C}$, la tensión arterial de $100 / 70$ $\mathrm{mmHg}$ y la saturación de oxígeno del $95 \%$. La faringe estaba ligeramente hiperémica y se apreciaba una inflamación difusa muy dolorosa en la parte lateral izquierda del cuello. La auscultación cardíaca era rítmica a 130 lat/min sin soplos. La auscultación pulmonar y la exploración abdominal eran normales. Entre los datos analíticos al ingreso destacaban: leucocitos $14,7 \times 10^{9} / 1$ (88\% neutrófilos), plaquetas $26 \times 10^{9} / \mathrm{l}$, VSG $59 \mathrm{~mm} / \mathrm{h}$, proteína C reactiva $34 \mathrm{mg} / \mathrm{dl}$, bilirrubina $1,8 \mathrm{mg} / \mathrm{dl}$, GGT $129 \mathrm{U} / \mathrm{l}$ y LDH $451 \mathrm{U} / \mathrm{l}$. El estudio de coagulación fue normal. La radiografía de tórax al ingreso mostró tenues imágenes nodulares en LSD y LSI. A las 12 horas de su extracción en urgencias se observó el crecimiento en los frascos anaerobios de los hemocultivos de un bacilo gram negativo. Se inició tratamiento con penicilina G sódica ( $6 \mathrm{mU} / 6 \mathrm{~h})$ y se realizó una ecografía de cuello que mostró signos de trombosis en la vena yugular externa izquierda y en el inicio de la yugular anterior izquierda, así como una zona flemonosa en la región paralaríngea izquierda. La vena yugular interna estaba permeable. El bacilo se identificó como F. necrophorum y fue sensible a penicilina y clindamicina. A las 24 horas de iniciado el tratamiento su situación clínica empeoró, presentando ligera hemoptisis, severa insuficiencia respiratoria con extensa afectación radiológica bilateral (Fig. 1) e inestabilidad hemodinámica, requiriendo ingreso en UCI donde precisó ventilación mecánica y medicación vasoactiva, añadiéndose al tratamiento clindamicina $(600 \mathrm{mg} / 6$

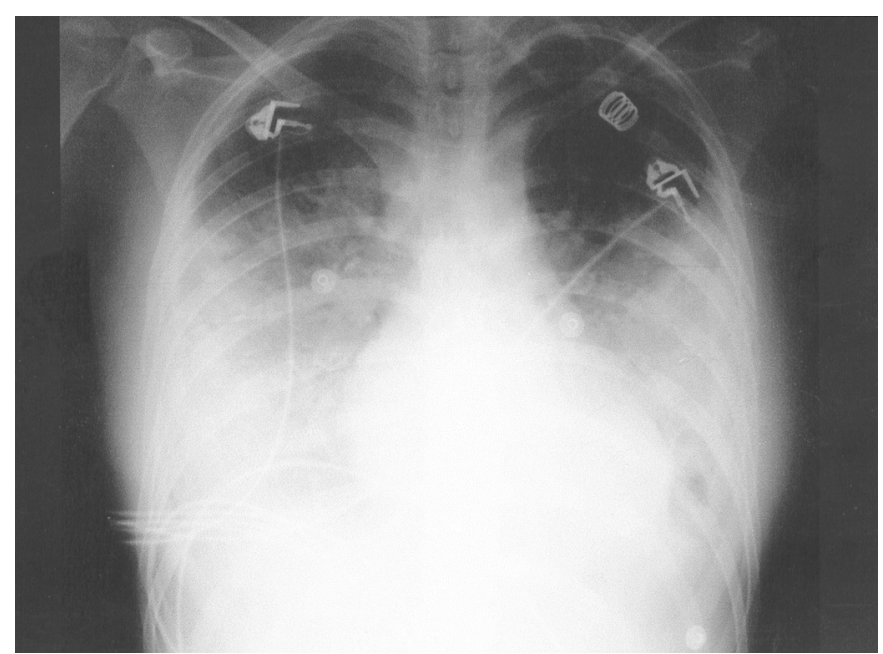

Fig. 1. Radiografía de tórax en la que se observa una extensa ocupación alveolar bilateral de campos medios e inferiores. h). Un TAC cervical confirmó los datos ecográficos. Un TAC de tórax realizado a los 5 días del ingreso (Fig. 2) mostró varias imágenes nodulares de contornos mal delimitados, algunas cavitadas, compatibles con émbolos sépticos, áreas de condensación alveolar en LSI, LM y LID y derrame pleural bilateral. Se evacuó 1 L de líquido pleural derecho hemorrágico cuyo cultivo fue negativo. Un ecocardiograma y una ecografía abdominal fueron normales. Ante la persistencia de la fiebre, al octavo día de ingreso se procedió a la resección de la vena yugular externa y ligadura de la yugular anterior. Tras 18 días de estancia en UCI fue dada de alta en situación clínica estable, aunque persistía fiebre diaria en torno a $39^{\circ} \mathrm{C}$ e importante afectación radiológica pleuroparenquimatosa inferior derecha. Los hemocultivos de control, ASLO y la serología de Coxiella, Chlamydia, Legionella, citomegalovirus, VEB y virus de la inmunodeficiencia humana fueron negativos. Se detectó frente a $M$. pneumoniae anticuerpos IgM (índice de ELISA de 1.85) y seroconversión (título de IFI de 1:1280 en la muestra obtenida a los 4 días del ingreso y de 1:5120 a los 21 días). A los 22 días del ingreso se añadió levofloxacino oral, y 48 horas después la enferma quedó totalmente afebril y se apreció una evidente mejoría de la radiografía de tórax. Fue dada de alta con clindamicina (hasta completar 6 semanas) y levofloxacino (hasta completar 3 semanas).

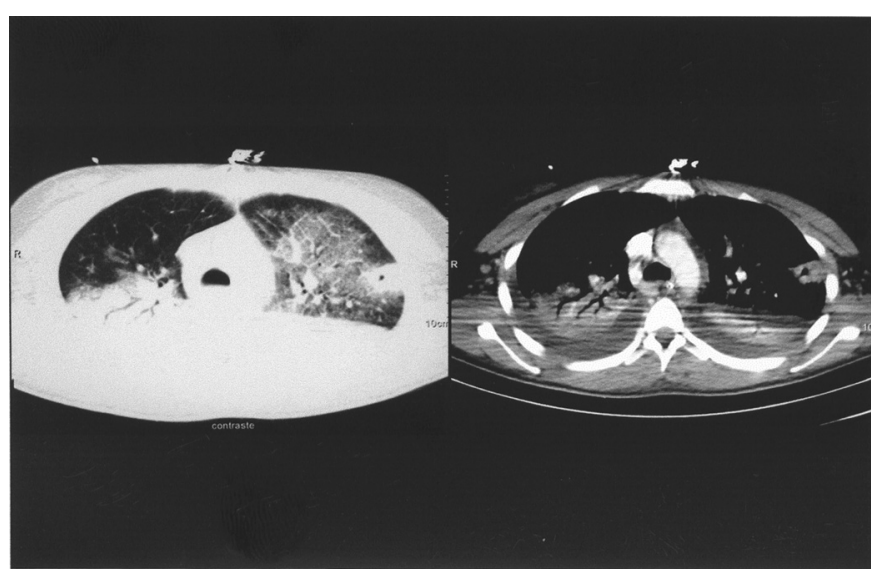

Fig. 2. Tomografía computarizada torácica con contraste. En LSI se observa un nódulo periférico cavitado y un área de vidrio deslustrado en su segmento anterior. En segmentos posteriores existen áreas de condensación y atelectasia así como derrame pleural bilateral.

\section{DISCUSIÓN}

Lemierre (1) dijo que la clínica de este síndrome es tan característica que permite su diagnóstico antes de conocer los resultados bacteriológicos, incluidos los hemocultivos. En nuestro caso la sospecha inicial fue de mononucleosis infecciosa y al diagnóstico se llegó sólo tras conocer el resultado de los hemocultivos, aunque el rápido crecimiento del bacilo permitió una confirmación diagnóstica y un tratamiento relativamente precoz. Esto fue debido sin duda a la falta de familiaridad con una enfermedad muy infrecuente. En un estudio realizado en Dinamarca desde 1990 hasta 1995 su incidencia fue de 0,8 casos por millón de habitantes y año (6). Sin embargo, conviene volver a recordar esta enfermedad porque todo parece apuntar a su reaparición $(3,6,7)$, que se ha atribuido al uso más restrictivo de penicilinas en las infecciones faríngeas a favor de antibióticos como los macrólidos que no son activos frente a $F$. necrophorum.

El cuadro se caracteriza por escalofríos y fiebre alta a los 3-7 días de una faringoamigdalitis (cuya clínica puede ser leve 
o incluso pasar inadvertida), dolor y tumefacción ipsilateral del cuello a lo largo del músculo esternocleidomastoideo, expresión de la tromboflebitis de la vena yugular interna, y finalmente abscesos metastásicos a distancia, principalmente en pulmón (en el 80-85\% de los casos) y grandes articulaciones $(15 \%)(7,10,11)$. El dolor abdominal difuso es un síntoma frecuente, puede existir hiperbilirrubinemia subclínica (30$50 \%$ ), a veces asociada a hepatomegalia (15\%), y trombocitopenia (24\%) (6,7,11-13). La afectación pulmonar se presenta en forma de infiltrados bilaterales múltiples de aspecto nodular, a veces cavitados, y con frecuencia existe efusión pleural (40-50\%) (11,14,15). Sus manifestaciones clínicas también suelen ser sugestivas de embolización pulmonar: dolor pleurítico (30\%), disnea (24\%) y hemoptisis (8\%), y casi el $16 \%$ de los pacientes requieren ventilación mecánica por insuficiencia respiratoria grave (11). En nuestro caso, con la excepción de la localización de la tromboflebitis, el cuadro clínico fue muy característico. Clásicamente, el síndrome de Lemierre se caracteriza por tromboflebitis de la vena yugular interna; sin embargo, la tromboflebitis puede ocurrir en cualquier vena de la cabeza y cuello $(3,16)$.

$F$. necrophorum, a diferencia de otras bacterias anaerobias, tiene una capacidad inusual de invasión en ausencia de enfermedades subyacentes debido a la producción de unas toxinas distintas de las de otros anaerobios. También estimula la agregación plaquetaria $(7,10,17)$, lo que explica la frecuente presencia de trombopenia en esta infección. Además, la coagulación intravascular causada por esta agregación plaquetaria puede contribuir a establecer un ambiente anaerobio que favorece el crecimiento de $F$. necrophorum (7).

Aunque $F$. necrophorum se comporte como un patógeno primario capaz de causar enfermedad invasiva por sí mismo, una infección primaria faríngea viral o bacteriana puede favorecer el desarrollo del cuadro. Varios de los casos descritos de síndrome de Lemierre están precedidos de infección por otros microorganismos, especialmente por el VEB (3-5). En nuestro caso, coexiste una infección por $M$. pneumoniae que, al igual que en los otros 2 casos descritos en la literatura $(8,9)$, pudo favorecer la invasión local y posterior bacteriemia por $F$. necrophorum. Inicialmente no se concedió importancia al elevado título de anticuerpos detectados frente a $M$. pneumoniae al inicio del cuadro, quizás por la situación de extrema gravedad que presentaba la enferma, con un diagnóstico ya por entonces de certeza, y lo excepcional de un cuadro severo por M. pneumoniae. Aunque es difícil de determinar con exactitud, creemos que la contribución real de M. pneumoniae en el proceso infeccioso de este caso fue importante: al menos la fiebre y la afectación pleuroparenquimatosa basal derecha no se resolvieron hasta la introducción de un antibiótico activo frente a este patógeno.

La antibioterapia de esta infección debe ser prolongada dada su naturaleza endovascular, el tratamiento anticoagulante sigue siendo motivo de controversia, y la ligadura de los vasos trombosados puede ser necesaria en caso de progresión de la sepsis o de la embolización a pesar del tratamiento médico $(3,7,18-20)$.

Los clínicos debemos saber reconocer esta grave y quizás no tan rara enfermedad, el síndrome de Lemierre, que es principalmente un diagnóstico clínico, y saber que puede coexistir o seguir a otras infecciones, para valorar correctamente cualquier dato clínico o analítico al respecto, más aún cuando éstas pueden ser ya de por sí también clínicamente importantes.

\section{Bibliografía}

1. Lemierre A. On certain septicemias due to anaerobic organisms. Lancet 1936; 1: 701-703.

2. Sinave CP, Hardy GJ, Fardy PW. The Lemierre syndrome: suppurative thrombophlebitis of the internal jugular vein secondary to oropharyngeal infection. Medicine 1989; 68: 85-94.

3. Ramírez S, Hild TG, Rudolph CN, Sty JR, Kehl SC, Havens P, et al. Increased diagnosis of Lemierre syndrome and other Fusobacterium necrophorum infections at a children's hospital. Pediatrics 2003; 112: 380-385.

4. Moller K, Dreijer B. Post-anginal sepsis (Lemierre's disease): a persistent challenge. Presentation of 4 cases. Scand J Infect Dis 1997; 29: 191-194.

5. Dagan R, Powell KR. Postanginal sepsis following infectious mononucleosis. Arch Intern Med 1987; 147: 1581-1583.

6. Hagelskjaer LH, Prag J, Malczynski J, Kristensen JH. Incidence and clinical epidemiology of necrobacillosis, including Lemierre's syndrome, in Denmark 1990-1995. Eur J Clin Microbiol Infect Dis 1998; 17: 561565 .

7. Hagelskjaer Kristensen L, Prag J. Human necrobacillosis, with emphasis on Lemierre's syndrome. Clin Infect Dis 2000; 31: 524-532.

8. Abele-Horn M, Emmerling P, Mann JF. Lemierre's syndrome with spondylitis and pulmonary and gluteal abscesses associated with Mycoplasma pneumoniae pneumonia. Eur J Clin Microbiol Infect Dis 2001; 20: 263-266.

9. Meis JF, Polder TW, van de Kar P, Hoogkamp-Korstanje JA. Multiple brain abscesses and bacteremia in a child due to Fusobacterium necrophorum. Infection 1993; 21: 174-176.

10. Golpe R, Marín B, Alonso M. Lemierre's syndrome (necrobacillosis). Postgrad Med J 1999; 75: 141-144.

11. Chirinos JA, Lichtstein DM, Garcia J, Tamariz LJ. The evolution of Lemierre syndrome. Report of 2 cases and review of the literature. Medicine 2002; 81: 458-465.

12. Pulcini C, Vandenbos F, Roth S, Mondain-Miton V, Bernard E, Roger $\mathrm{PM}$, et al. Syndrome de Lemierre: à propos de 6 cas. Rev Méd Interne 2003; 24: 17-23.

13. Hoehn S, Dominguez TE. Lemierre's syndrome: an unusual cause of sepsis and abdominal pain. Crit Care Med 2002; 30: 1644-1647.

14. Screaton NJ, Ravenel JG, Lehner PJ, Heitzman ER, Flower CD. Lemierre syndrome: forgotten but not extinct-report of four cases. Radiology 1999; 213: 369-374.

15. Leugers CM, Clover R. Lemierre syndrome: postanginal sepsis. J Am Board Fam Pract 1995; 8: 384-391.

16. Nguyen-Dinh KV, Marsot-Dupuch K, Portier F, Lamblin B, Lasjaunias P. Lemierre syndrome: usefulness of CT in detection of extensive occult thrombophlebitis. J Neuroradiol 2002; 29: 132-135.

17. Forrester LJ, Campbell BJ, Berg JN, Barrett JT. Aggregation of platelets by Fusobacterium necrophorum. J Clin Microbiol 1985; 22: 245249.

18. Sherer Y, Mishal J, Leibovici O. Early antibiotic treatment may prevent complete development of Lemierre's syndrome: experience from 2 cases. Scand J Infect Dis 2000; 32: 706-707.

19. Nakamura S, Sadoshima S, Doi Y, Yoshioka M, Yamashita S, Gotoh H, et al. Internal yugular vein thrombosis, Lemierre's syndrome; oropharyngeal infection with antibiotic and anticoagulation therapy-a case report. Angiology 2000; 51: 173-177.

20. Álvarez A, Schreiber JR. Lemierre's syndrome in adolescent childrenanaerobic sepsis with internal jugular vein thrombophlebitis following pharyngitis. Pediatrics 1995; 96: 354-359. 